\title{
A ESCOLARIZAÇÃO DE JOVENS DE ASSENTAMENTO DO MST E SUA FORMAÇÃO PARA A EMANCIPAÇÃO HUMANA*
}

Natacha Eugênia Janata ${ }^{1}$

Resumo: O texto apresenta reflexões acerca da relação entre a escolarização de jovens em nível médio em uma escola de assentamento do MST e sua formação para a emancipação humana. As sínteses são oriundas da pesquisa de Doutorado em Educação que abordou de forma mais geral a temática acerca do trabalho, escolarização e militância de egressos do ensino médio do Colégio Estadual do Campo Iraci Salete Strozak, localizado no Assentamento Marcos Freire, em Rio Bonito do Iguaçu, no Paraná. O percurso metodológico da investigação envolveu a pesquisa bibliográfica sobre o tema, entrevista com 22 jovens egressos da escola, com a vice-diretora e a coordenadora pedagógica, bem como quatro lideranças do assentamento. Analisamos o Projeto Político Pedagógico da instituição, buscando a interseção com os depoimentos dos entrevistados, a fim de evidenciar os condicionamentos e as potencialidades na formação dos egressos. Ainda que os limites da sociabilidade do capital se imponham, concluímos sobre a importância e a contribuição dessa escola para a formação dos jovens.

Palavras-chave: Trabalho. Educação. Jovens. MST.

Abstract: The text presents reflections on the relationship between the schooling of young people in middle level in a school of MST settlement and their formation for human emancipation. The summaries are from doctoral research in education that addressed more generally the 
theme about the work, education and activism of high school graduates of the Colégio Estadual do Campo Iraci Salete Strozak, located in the Assentamento Marcos Freire, in Rio Bonito do Iguaçu, Paraná. The methodological research career involved the bibliographical research on the topic, interview with 22 young people graduating from the school, with the director and the pedagogical coordinator, as well as four leaders of the settlement. We analyze the pedagogical political project of the institution seeking the intersection with the testimony of the respondents, in order to highlight the constraints and capabilities in the training of graduates. Although the limits of sociality of capital if necessary, conclude about the importance and the contribution of this school for the formation of the young.

Keywords: Work. Educacion. Young people. MST. 
O presente texto é fruto da pesquisa de Doutorado em Educação realizado no período de 2008 a 2012 e busca socializar algumas reflexões e sínteses decorrentes do processo de investigação acerca do trabalho, escolarização e militância de jovens que fizeram sua escolarização de nível médio em uma escola de assentamento do MST.

Iniciamos o texto apresentado o lócus da pesquisa, o Colégio Estadual do Campo Iraci Salete Strozak², bem como caracterizando a investigação. Seguimos problematizando os pressupostos teóricos da formação almejada para os jovens e então finalizamos com reflexões e análises acerca da relação entre a escolarização dos egressos da escola pesquisada e a formação para a emancipação humana.

\section{O Colégio Estadual Iraci Salete Strozak e a pesquisa com egressos}

Não temas perguntar, companheiro!

Não te deixes convencer!

Compreende tudo por ti mesmo.

O que não sabes por ti, não o sabes. Confere a conta. Tens de pagá-la. Aponta com teu dedo a cada coisa e pergunta: "Que é isto? e como é?" Estás chamado a ser um dirigente.

Bertold Brecht

O Colégio Iraci ${ }^{3}$ está localizado em Rio Bonito do Iguaçu, município da região centro-oeste do Paraná, mais exatamente no Assentamento Marcos Freire, vinculado ao Movimento dos Trabalhadores Rurais Sem Terra. O Assentamento Marcos Freire 
é fruto da ocupação do maior latifúndio da região centro-oeste do Paraná, a Fazenda da madeireira Giacomet-Marodin, com pouco mais de oitenta mil hectares, numa extensão que envolvia três municípios, entre eles Rio Bonito do Iguaçu. Em 1996, mais de dez mil sem-terra, organizados pelo MST, marcharam em direção ao latifúndio, ocupando-o. Onde antes havia a exploração da terra para uso de apenas uma única família, tevese a criação dos Assentamentos Marcos Freire e Ireno Alves dos Santos nos quais se passou a produzir vida para cerca de 1,5 mil famílias (HAMMEL; SILVA; ANDREETTA, 2007).

No processo de luta pela democratização do acesso a terra, luta-se também pela educação e os trabalhadores rurais conquistaram nesse espaço a construção e o funcionamento de seis escolas municipais de Ensino Fundamental - anos iniciais, quatro escolas estaduais de Ensino Fundamental - anos finais, sendo duas destas também de Ensino Médio - uma com curso profissionalizante - Formação de Docentes, modalidade normal, em nível médio integrado. Esta última consiste no Colégio Estadual do Campo Iraci Salete Strozak, lócus de nosso estudo.

Constituiu-se objetivo geral da pesquisa compreender como ocorre a formação de jovens militantes do MST, com foco nos egressos do Ensino Médio do Colégio Estadual do Campo Iraci Salete Strozak, considerando a mediação entre a escolarização de nível médio, o trabalho, a militância e a continuidade dos estudos.

Os egressos do Colégio Iraci Salete Strozak perfaziam um conjunto de 138 jovens, dos quais 114 do Ensino Médio e 24 do curso de Formação de Docentes, em nível médio. Foram entrevistados 22 jovens, 15 dos quais haviam cursado o Ensino Médio e os demais o curso de Formação de Docentes. Entrevistamos também a equipe diretiva da escola (vicediretora e coordenadora pedagógica) e quatro lideranças do assentamento, bem como realizamos o estudo documental dos 
Projetos Político-Pedagógico dos anos de 2002 e 2009, além do projeto do Curso de Formação de Docentes (2008).

Quais seriam os determinantes na formação dos jovens do Colégio Estadual Iraci Salete Strozak? Como as experiências vividas nessa escola, especialmente no Ensino Médio, marcavam sua formação? Essas são algumas das questões que balizaram a pesquisa e que escolhemos para serem tratadas nesse texto.

Em termos de documentos oficiais o Colégio Iraci não dispunha de uma proposta específica para o Ensino Médio, apenas para o curso de Formação Docente, por isso utilizamos o Projeto Político Pedagógico da escola e do referido curso para discutir as concepções em torno da formação dos jovens nesse nível de ensino, ambos à luz dos referenciais específicos dessa área, que vêm debatendo sistematicamente a relação trabalho e educação no Ensino Médio e no integrado à educação profissional, bem como das compreensões filosóficas e pedagógicas educacionais elaboradas pelo MST, principalmente aquelas ligadas efetivamente com a questão da "Educação Básica de Nível Médio", assim denominada pelo próprio Movimento.

Consideramos os autores referenciados ao longo do texto como aqueles que têm sistematizado debates acerca dos fundamentos teóricos e metodológicos do Ensino Médio, principalmente no trato com sua integração à educação profissional, que tornam possíveis nossas análises tendo em vista nosso campo de estudo. Isso não significa necessariamente que a escola pesquisada em seu conjunto encontre neles seus fundamentos. A escolha desses autores ocorre por pelo menos quatro fatores correlatos: explicitação de um projeto histórico de sociedade contraposto ao capitalismo, como decorrência desse, a busca por uma formação omnilateral, o trabalho como princípio educativo, os sujeitos conferindo sentido às propostas e processos pedagógicos.

Nesse sentido, os aportes teóricos nos auxiliam na problematização da formação dos jovens no sentido da 
emancipação humana, horizonte maior tanto do Colégio Iraci, como identificado na pesquisa, quanto dos próprios autores. Adere-se a esse fato o MST os ter como referência nas suas formulações, o que pode ser evidenciado na publicação de dois dos seus documentos: o Boletim da Educação n. 11, intitulado Educação Básica de Nível Médio nas Áreas de Reforma Agrária, uma coletânea de textos de estudos que serviu para fundamentar as discussões do $1^{\circ}$ Seminário Nacional sobre Educação Básica de Nível Médio nas Áreas de Reforma Agrária, ocorrido em setembro de 2006; além de um texto de Caldart (2010) denominado "Educação profissional na perspectiva da educação do campo". Importante registrar que tais documentos sintetizam um movimento desencadeado pela demanda da formação da juventude dos assentamentos que vem ganhando força nos debates do MST a partir principalmente de 2005.

\section{O Ensino Médio e a relação trabalho educação}

A forma dual assumida pela educação brasileira, tornada mais visível quando nos referimos ao Ensino Médio, explicita a divisão social do trabalho no capitalismo e nesse sentido não há pretensões de resolvê-la por meio da escola, anseio este que Kuenzer (2005) denomina de "ingenuidade ou má-fé". Entretanto, tendo a escola pública como também espaço de luta da classe trabalhadora é que apreendemos elementos necessários na constituição de um projeto formativo para o Ensino Médio, que alterem sua "forma, método e conteúdo", como nos traz Frigotto (2004), com vistas a contribuir nos processos emancipatórios dos seres humanos, nesse caso dos sujeitos jovens assentados.

A articulação entre o trabalho, a ciência e a cultura é compreendida como o pilar fundamental na defesa de um 
projeto de Ensino Médio unitário, como pode se constatar na afirmação de Ramos (2004, p. 51):

$\mathrm{Na}$ construção de novas perspectivas para o Ensino Médio unitário - como momento histórico da formação de sujeitos individuais e coletivos, que congrega em si a síntese do diverso -, o trabalho, a ciência e a cultura são princípios estruturantes e devem ser resgatados como meio para a compreensão e a transformação do mundo atual.

Essas dimensões da prática social são concebidas da seguinte forma: o trabalho, em seu duplo sentido, ontológico e histórico, enquanto manifestação do próprio ser humano, realização humana, porém também como expressão de determinado modo de produção; a ciência, como os conhecimentos mais avançados que fundamentam as técnicas, que geram o avanço produtivo em sua inerente contradição entre capital e trabalho, fundada nas relações sociais de produção capitalista; e a cultura, como bens da humanidade nas suas diferentes formas de criação, símbolos, representações, valores éticos e estéticos (FRIGOTTO; CIAVATTA, 2004; RAMOS, 2006).

Frigotto e Ciavatta (2004, p. 21) dão um sentido para o trabalho como base do Ensino Médio, afirmando que ele deve ser compreendido "[...] como princípio educativo no sentido da politecnia ou da educação tecnológica [...]", termos esses que encontramos em passagens dos textos de Marx e Engels já citados na introdução da pesquisa.

Para apreender o que pode significar a politecnia ou educação tecnológica no Ensino Médio, retomamos a compreensão definida por Marx nas "Instruções aos Delegados”. Este afirma a "instrução tecnológica" como aquela que leva a transmissão dos "princípios gerais de todos os processos de produção", juntamente com a iniciação da criança e do jovem no "[...] uso 
prático e manejo dos instrumentos elementares de todos os ofícios." (MARX, 1982, p. 84).

A relação teoria e prática é colocada com ênfase e aparece também em Engels (1982) nos "Princípios básicos do comunismo". Além de apontar a combinação da "educação e o trabalho fabril" como medida para atacar a propriedade privada, Engels, ao refletir sobre quais as consequências do seu fim, afirma num exercício de projeção que a "indústria explorada em comum" e de forma planificada por toda a sociedade implica homens com "aptidões integralmente desenvolvidas", em condições de abranger todo o sistema produtivo. Nesse sentido:

A educação permitirá aos jovens passar rapidamente por todo o sistema de produção; colocá-los-á em condições de passar sucessivamente de um ramo da produção para outro, conforme o proporcionem as necessidades da sociedade ou suas próprias inclinações. Retirar-lhes-á, portanto, o caráter unilateral que a actual divisão do trabalho impõe a cada um deles. (ENGELS, 1982, p. 90).

Importa entender que Engels se refere a algo que se contrapõe ao existente, afinal sob o jugo do domínio do capital sobre a vida, é ele quem cria as necessidades e não as relações sociais. Em outras palavras, as necessidades no capitalismo não são da produção nem dos seres humanos e sim do capital. Nesse sentido, a flexibilidade como princípio do processo de trabalho, ainda que façam os trabalhadores passarem por diferentes ramos não rompe com a os limites da unilateralidade humana, já que a existência da propriedade privada permanece e, com ela, os processos de alienação.

Marx (2010, p. 552) trata desses limites afirmando-os como o "aspecto negativo" da indústria moderna, com sua "base técnica revolucionária”, que de um lado transforma "constantemente a divisão do trabalho dentro da sociedade", exigindo "fluidez das 
funções", mas que ao manter sua forma capitalista gera uma "[...] contradição absoluta (que) elimina toda a tranqüilidade, solidez e segurança da vida do trabalhador."

No entanto, em sua positividade, afirma a possibilidade do trabalhador em se sentir "menos molusco e mais homem", posto que a indústria moderna impõe a "variação dos trabalhos" como "lei geral e social" e em decorrência disso a necessidade da "maior versatilidade possível do trabalhador" e a "disponibilidade absoluta do ser humano para as necessidades variáveis do trabalho" e não da exploração capitalista (MARX, 2010, p. 552553).

Encontramos argumentações para compreender como a perspectiva de Ensino Médio integrado, assumida por Frigotto, Ciavatta e Ramos (2005) como a "travessia contraditória", faz sentido mediante as necessidades de reprodução imposta aos jovens da classe trabalhadora, que, se de um lado têm o direito ao acesso a educação de nível médio, de outro precisam se inserir no sistema produtivo para garantir sua existência. Como afirmam os autores:

Por isso, o Ensino Médio integrado ao ensino técnico, conquanto seja uma condição social e historicamente necessária para a construção do Ensino Médio unitário e politécnico, não se confunde com ele porque a conjuntura da realidade atual assim não o permite. Não obstante, por buscar conter os elementos de uma educação politécnica, contém também os gérmens de sua construção. (FRIGOTTO; CIAVATTA; RAMOS, 2005, p. 15).

Como pensar essa integração na particularidade dos jovens de assentamento, que têm o trabalho da agricultura, ou mais amplamente, do campo, como central para sua sobrevivência? $\mathrm{O}$ já referido Documento Final do $1^{\circ}$ Seminário Nacional 
sobre Educação Básica de Nível nas áreas de Reforma Agrária (MST, 2010) apresenta dez ideias-força na elaboração de uma concepção de Ensino Médio com os pressupostos teóricos que consideram a contradição entre capital e trabalho e a necessidade histórica de superação do capitalismo, sem deixar de lado a particularidade de sua expressão no campo. Entre elas destacamos algumas a seguir.

Pensar uma escola partindo de sujeitos concretos, individuais e coletivos, integrando a identidade de "Sem Terra, de camponeses, de classe trabalhadora". Ter como ponto de partida a materialidade, isto é, os sujeitos jovens concretos, é uma perspectiva também de Frigotto (2004, p. 27), que coloca a importância desse deslocamento de uma visão abstrata para um entendimento "[...] histórico dos processos formativos e de construção de conhecimento nesse nível de ensino."

Um dos objetivos da "Educação Básica de Nível Médio" para o MST (2010) é "consolidar nos jovens uma visão de mundo articulada a valores e identidades". Assim, é preciso que tenham uma sólida formação acerca dos conhecimentos da ciência, que os ajudam a compreender a formação das diferentes dimensões humanas e isso só é possível pelo vínculo com a vida "real".

No que concerne ao debate da inclusão ou não da profissionalização do jovem a defesa é a de que haja a articulação entre uma "formação humana integral" e as demandas de preparação para intervenções mais diretas, seja pela participação nos processos produtivos e geração de renda ou ainda na vida cultural dos assentamentos, bem como na própria militância. Assim, o MST (2010, [s.p.]) entende que

[...] todas as escolas de nível médio devem ter como um de seus objetivos a formação geral e específica para o trabalho (e a educação tecnológica e técnica que lhe corresponde), tratando-a mesmo com um dos eixos 
articuladores do currículo, mas sem necessariamente incluir a oferta de cursos técnicos-profissionalizantes.

Outro elemento é que o Movimento corrobora da concepção de uma formação integral e unitária, "para todos os jovens em todas as escolas". O trabalho é princípio educativo a fim de que os jovens possam "compreender os processos produtivos mais complexos e os que são próprios dos assentamentos, do campo", sendo necessária a garantia de uma organicidade entre os processos educativos, o currículo e os eixos de desenvolvimento dos assentamentos que vêm discutindo com mais ênfase a cooperação e a agroecologia (MST, 2010, [s.p.]).

Por fim, destacamos ainda como uma preocupação do MST (2010, [s.p.]) a dimensão cultural, a formação ética e estética, "garantindo uma leitura crítica do modo de viver predominante na sociedade capitalista" e também acesso aos equipamentos e bens culturais, como a literatura, cinema, teatro, dança, artes plásticas, música.

A seguir adentramos no contexto do Ensino Médio do Colégio Iraci a partir do Projeto Político Pedagógico da escola (PPP, 2002; PPP, 2009) e do Curso de Formação Docente (PPPFD, 2008), elencando algumas problematizações acerca da formação dos jovens, seus condicionamentos e possibilidades.

\section{A educação de nível médio no Colégio Iraci}

O que poderia ser relevante em relação à organização do trabalho pedagógico da escola para pensar sobre a formação dos jovens no Ensino Médio do Colégio Iraci? Partimos para a (re)escuta das entrevistas e as anotações no diário de campo, a fim de que nos dessem os possíveis elementos orientadores das 
reflexões. Além disso, procedemos à leitura analítica dos PPP da escola e do Curso de Formação de Docentes, destacando pontos que se cruzavam com as falas dos entrevistados.

Dessa forma, as reflexões acerca da organização do trabalho pedagógico da educação de nível médio no Colégio Iraci tomaram por base elementos significativos apontados nas falas dos jovens que trouxeram marcadamente a avaliação, a dimensão cultural e a história/memória do assentamento como formadores.

O PPP (2009) do Colégio está estruturado em três itens maiores denominados de Marco Situacional, Marco Conceitual e Marco Operacional. No primeiro, com o título "À luz da história: o marco situacional" é abordado a origem da escola e destaca-se um diagnóstico das problemáticas enfrentadas na apropriação dos conhecimentos pelos educandos bem como na concretização da proposta de avaliação. Traz-se a característica específica de ser uma das Escolas Base das Escolas Itinerantes no Paraná, tratando das questões que envolvem constituir-se como tal. É apresentado o "Projeto Viver em Harmonia", organizado em oficinas de coral, teatro, música e artesanato, acontecendo no contraturno e atendendo aos estudantes interessados. Por fim, a estrutura física e pedagógica da escola é descrita destacando a falta de espaço como uma situação problemática.

No Marco Conceitual apresentam-se os fundamentos teóricos que orientam as práticas pedagógicas, trazendo os objetivos da escola e demarcando sua identificação com os princípios da educação do MST, tendo como referência central a Pedagogia do Movimento (CALDART, 2000). Assumem também eixos das "Diretrizes Estaduais para a Educação do Campo", documento orientador da Secretaria Estadual de Educação do Paraná. Por fim, apresentam os pressupostos da organização curricular em ciclos de formação humana e por área do conhecimento.

No Marco Operacional explicita-se a estruturação decorrente das concepções assumidas iniciando pela organização curricular 
dos três níveis da Educação Básica atendidos pelo Colégio Iraci, seguido da metodologia de ensino organizada em três momentos - Estudo da Realidade, Organização do Conhecimento, Aplicação do Conhecimento. Parte-se para o detalhamento das etapas e instrumentos de avaliação, que envolvem o registro de cada educando na pasta de acompanhamento e no parecer descritivo e o Conselho de Classe Participativo. Por fim, é explicado como procedem na organização dos educandos e coletivo de educadores e como deve ocorrer o processo de acompanhamento e avaliação do PPP da escola.

De acordo com Hammel, Silva e Andreetta (2007), o Ensino Médio começou a ser implantado em 1999, após uma ocupação no Núcleo Regional de Educação, instância descentralizada da SEED. O intuito foi o de garantir o atendimento aos educandos que haviam finalizado o ensino fundamental, em sua maioria, nas turmas de correção de fluxo ofertadas pelo próprio Colégio em 1998, primeiro ano de funcionamento legal do estabelecimento.

Considerando o recorte histórico da pesquisa, 2001-2009, e com base nos relatórios anuais do Colégio Iraci, bem como nas informações prestadas pela vice-direção e por um funcionário com atividade na secretaria do Colégio constatamos que a primeira turma encerrou em 2001 com dezesseis educandos, dos quais dez cursaram os três anos do Ensino Médio na escola e no momento da pesquisa de campo apenas um destes ainda residia no assentamento. Em 2009 houve 34 formandos, sendo que 26 fizeram todo o Ensino Médio no colégio estudado e 11 permanecem no assentamento.

A organização curricular segue a legislação nacional e orientações estaduais e tem como concepção os Ciclos de Formação Humana, apoiados em Arroyo (1999) e Freitas (2001, 2003). Como consta no PPP (2009), a matriz curricular tem a carga horária de cada disciplina dividida o mais igualitariamente possível, pela compreensão de que não há supremacia de uma 
disciplina em detrimento de outras. A distribuição das aulas busca agregar a maior carga horária possível dos professores em cada ciclo, abrindo para a possibilidade de que assumam mais de uma disciplina respeitando o princípio da área de conhecimento e a formação acadêmica dos educadores.

O Ensino Médio é identificado como o ciclo da juventude, tendo como objetivo uma formação geral, sólida, pautando a vinculação entre o contexto local e universal buscando apropriarse de conhecimentos universais e socialmente comprometidos com a transformação da sociedade e da juventude o que exige uma análise do mundo do trabalho (PPP, 2009, p. 45-46).

O Curso de Formação Docente caracteriza-se pela modalidade de Ensino Médio integrado à educação profissional. Sua constituição é decorrente de dois processos que ocorreram simultaneamente. Um deles foi o fato do Colégio assumir, em 2004, a função de Escola Base das Escolas Itinerantes no estado o que gerou a demanda de formação dos educadores que iriam atuar nelas. O Colégio, em conjunto com o MST, elaborou a proposta de um curso de formação para educadores do campo, em regime de alternância, tendo em sua concepção os princípios educativos do MST, com o intuito de atender aos jovens dos assentamentos de Rio Bonito do Iguaçu bem como aos educadores que já atuavam nas Escolas Itinerante, enviando-o à Secretaria de Estado da Educação do Paraná (SEED) (HAMMEL; JANATA, 2010).

O outro processo se deu em 2003 quando a SEED, através do Departamento de Educação Profissional, iniciou um momento de reorganização do Ensino Médio. Com a perspectiva da integração à educação profissional, contrapôs-se ao desmonte da escola pública e da educação profissional integrada ao Ensino Médio executada pelo Governo Jaime Lerner (1995-2002), que implantou as reformas estruturais neoliberais no Paraná, tendo o amparo legal em nível federal com o Decreto 2.208/97 (GARCIA, 2009). 
O Ensino Médio integrado defendido pela SEED a partir do Governo Requião (2003-2010) tem seus pressupostos teóricos nas formulações dos autores referendados no início desse capítulo, Frigotto, Ciavatta e Ramos, que tomam a articulação trabalho, ciência e cultura como central para a formação. Nas palavras de Frigotto (2005, p. 74):

Trata-se de desenvolver os fundamentos das diferentes ciências que facultem aos jovens a capacidade analítica tanto dos processos técnicos que engendram o sistema produtivo quanto das relações sociais que regulam a quem e a quantos se destina a riqueza produzida. [...] Trata-se de uma formação humana que rompe com as dicotomias geral e específico, político e técnico ou educação básica e técnica, heranças de uma concepção fragmentária e positivista da realidade humana.

No bojo da retomada dos cursos profissionalizantes integrados passa a ser ofertado o Curso de Formação de Docentes da Educação Infantil e dos Anos Iniciais do Ensino Fundamental - Normal, em nível médio, a partir de 2004. O início da expansão desse curso na rede estadual ocorreu pela autorização de funcionamento em 31 estabelecimentos que demonstraram interesse e estrutura adequada para viabilizá-lo e nos anos seguintes ampliando a oferta para 113 cursos em todo o Paraná (SEED, 2006). O Portal Educacional do Paraná, página virtual oficial da Secretaria de Educação, registra que em 2010 havia 134 cursos de formação docente, com o total de 20.249 matrículas, o que representa $46 \%$ de todos os cursos integrados da rede estadual.

Os dois condicionantes resultaram na negação da proposta específica para formação de educadores do campo, encaminhada pela escola e na aprovação de funcionamento do curso Normal, em nível médio, nos moldes do ofertado pela SEED. O Projeto 
Político Pedagógico do Curso de Formação de Docentes (PPPFD, 2008) do Colégio Iraci afirma que apesar de não viabilizar o atendimento aos educadores das Escolas Itinerantes, conforme demanda inicial, o referido curso possibilitou um avanço no sentido de possibilitar alternativa de profissionalização aos jovens do campo no espaço em que vivem, na contraposição de grande parte da oferta de Ensino Médio, que ocorre nos centros urbanos. O que vem ocorrendo é o processo inverso, estudantes que residem na sede do município se deslocam para o Assentamento a fim de terem acesso ao curso, já que na única escola desse espaço não há oferta da educação profissional integrada ao médio. Segundo o PPP-FD (2008, p. 4):

O colégio vive a experiência de ser o primeiro a ofertar um curso de formação de docentes dentro de um assentamento da Reforma Agrária, apesar da proposta da SEED não atentar para esta especificidade. O Colégio Iraci Salete tem, dentro dos limites apresentados pela escola pública, buscado formar educadores e educadores na perspectiva de uma educação do campo que corresponda aos princípios de formação que considere a especificidade da educação escolar, considerando as questões e lutas pelo direito à terra e justiça social. [...] comunga dos princípios educativos do MST e das diretrizes da Educação do Campo.

A matriz curricular prevê 4,8 mil horas distribuídas em quatro anos letivos, incluindo a base nacional comum e a parte diversificada do Ensino Médio, bem como a formação específica com disciplinas dos fundamentos da educação, da gestão escolar, das metodologias de ensino e o estágio supervisionado, denominado prática de formação, que do total abrange 800 horas. O curso busca formar educadores para atuarem com a educação infantil e anos iniciais do ensino fundamental, em 
especial nos acampamentos e assentamentos, no intuito de que entendam "[...] o trabalho pedagógico de forma crítica e coerente com princípios de humanização e emancipação de sujeitos históricos e sociais." (PPP-FD, 2008, p. 5).

Quanto às concepções orientadoras, o PPP-FD (2008) cita como referências o PPP do Colégio Iraci, a Proposta Pedagógica Curricular do Curso de Formação de Docentes da Educação Infantil e Anos Iniciais do Ensino Fundamental, em Nível Médio, na Modalidade Normal, da SEED (2006), os princípios da educação do campo e do MST.

Destaca-se o trabalho como princípio educativo, a práxis como princípio curricular e o direito da criança ao atendimento escolar como elementos chave da proposta, tendo como perfil profissional esperado

[...] a posse de domínio teórico e prático das diferentes teorias pedagógicas que explicam o processo educativo e a formação humana, das concepções históricas para que dêem conta de contextualizar a realidade brasileira, especialmente a do campo, da legislação educacional vigente no que diz respeito à infância, adolescência e juventude, das experiências educativas produzidas pelos movimentos sociais do campo, especialmente no que se refere a Educação do Campo. Além disto, espera-se que até a conclusão do curso os educandos apresentem capacidade de saber elaborar/planejar práticas educativas, recursos didáticos e avaliativos do processo de ensino-aprendizagem, bem como, propostas pedagógicas e plano de ensino. Dominem técnicas de comunicação e expressão, saibam fazer orçamentos simples, controlar gastos, fazer prestações de contas, coordenar reuniões, trabalhar em equipe, respeitar as decisões coletivas, argumentar sobre diferentes pontos de vistas, diagnosticar problemas e propor soluções. Por fim que cultivem valores de solidariedade, de 
esperança, hábitos e princípios traduzidos numa postura centrada no ser humano e no ser humano educador, na preocupação com o bem estar do coletivo, na tomada de decisão e posicionamento diante das situações reais do processo educativo e social, assumindo a postura dialógica, respeitando as diferenças do grupo em que está inserido. (PPP-FD, 2008, p. 7-8).

Diferentes tempos/espaços são considerados como formativos e compõem-se, sinteticamente, de: Tempo Seminário, abrangendo o Seminário dos Pensadores, o Seminário de Socialização e Avaliação dos Estágios e o Seminário de Educação do Campo e Infância; Tempo/espaço de avaliação/reflexão, constituído do Diário de Reflexão Pessoal, Caderno de Estágio e Caderno de Horas, Conselho de Classe Participativo; Tempo Oficina, como complementação de estudos, com Oficina de Comunicação e Expressão; Reforço da Aprendizagem, de Contação de História, Ciranda Infantil, Teatro, Brinquedos e Brincadeiras; Tempo Trabalho, que inclui a auto-organização dos estudantes para realizarem os seminários e a Aula Inaugural, por fim, o Trabalho de Conclusão de Curso, com a elaboração de um artigo relatando as experiências do estágio, articulando com os conhecimentos das demais disciplinas (PPP-FD, 2008).

Tais tempos/espaços formativos ocorrem, sobretudo, no interior das 200 horas anuais destinadas à Prática de Formação, mais conhecido como estágio, que se constitui como o eixo articulador das disciplinas, principalmente as que integram a parte da Formação Específica.

Uma problemática presente no curso diz respeito ao elevado índice de evasão/desistência, posto que as turmas encerram com menos da metade dos matriculados no primeiro ano. A vice-diretora ${ }^{4}$ informou que tal fato tem causas diversas, entre elas a sobrecarga e disponibilidade que o curso exige, sendo que muitos educandos também precisam auxiliar no trabalho 
em suas casas, a rotatividade das famílias no assentamento, a gravidez na adolescência, que acaba gerando a desistência das meninas, maioria no curso.

No ano de 2008 houve a formatura da primeira turma com 13 educandos, dos quais 11 moças e três rapazes. Do total, cinco permaneciam no assentamento e apenas duas exerciam atividades correlatas à profissionalização. Em 2009, formou-se a segunda turma com dez moças e um rapaz, sendo que ainda residiam no assentamento quatro jovens. Do total dos onze formados, quatro atuavam em espaços correspondentes aos da formação docente.

As entrevistas indicaram três elementos marcantes na organização do trabalho pedagógico do Colégio Iraci, a avaliação, a dimensão cultural e a valorização da história/memória do assentamento. Nesse sentido, pudemos perceber que as informações trazidas nas falas, ao serem confrontadas com os documentos da escola, nomeadamente o PPP $(2002,2009)$ e o PPP-FD (2008), enriqueceram a compreensão das práticas pedagógicas vivenciadas na escola e que não necessariamente se fazem presente nas referidas sistematizações.

A avaliação, a cultura e a história, elementos das práticas pedagógicas do Colégio Iraci

Consideramos pertinente apreender mais detalhadamente os três componentes ressaltados pelos jovens, buscando articular os dados das entrevistas e dos dois PPPs com as discussões acerca da educação e Ensino Médio das quais corroboramos. Abordamos inicialmente a questão da avaliação, em seguida da dimensão cultural e por fim da história/memória.

O diálogo a seguir, resultado da entrevista coletiva realizada em 8 de julho de 2010, traz reflexões sobre a avaliação no Colégio Iraci 
Thaile - Foi mais a questão da prática pedagógica daqui mesmo que ajudou a mudar minha visão, construiu minha identidade do campo, digamos assim, de assentada, Sem Terra, pra ficar aqui, porque agora eu não pretendo sair tão cedo. Aí, eu lembro do Conselho de Classe Participativo, que é muito legal e a gente não tinha lá. [...] Acho que pela escola ser vinculada com o Movimento, ser organizada com princípios organizativos do Movimento, acho que a palavra coletividade, que é muito forte aqui, que aqui a gente tem voz e vez e nos outros colégios que eu estudei não era assim.

Natacha - O que você achou do Conselho de Classe?

Thaile - Porque a gente podia fazer uma auto-crítica, podia melhorar, podia dar a opinião da gente sobre o que podia melhorar na escola também, na metodologia dos professores, tudo, a gente podia avaliar, ser avaliado e fazer uma auto-crítica, [...] no sentido de melhorar.

Outro trecho ${ }^{5}$, em resposta à indagação sobre se identificavam algo de novo ou diferente no Colégio Iraci em relação a outras escolas que conheciam também traz a avaliação como componente pedagógico significativo:

Thaile - Acho que muita coisa, a organicidade da escola. Tipo a formação por ciclos e não seriada, como é nas escolas tradicionais, o Conselho de Classe Participativo, várias coisas que a escola se mobiliza no sentido de fazer diferente, de tentar mudar.

Sonia - O aluno estuda não pra ter nota, né. É mais do que isso.

Thaile - Tem a questão da avaliação aqui que tem os pareceres, né. $\mathrm{Na}$ escola que eu tinha estudando antes eu nunca tinha visto, nem sabia o que era, era só a avaliação por questões.

Joice - O conselho de classe também.

$[\ldots]$ 
Carla - Em relação à escola que eu estudava, foi a única experiência que eu tive. Antes era a escola tradicional, avaliação pela nota. Primeira vez na vida que ouvi falar de avaliar, poder avaliar um professor foi aqui na Iraci. Acho que isso é uma coisa marcante, o conselho de classe. Uma outra proposta assim, fazer que o educando entenda a função do professor. Até então o professor parecia aquele segundo pai, segunda mãe, intocável, aquela coisa! Acho que a escola não tira aquilo de respeitar, mas há funções e que a gente pode sim, - porque não? -, avaliar todas elas. (Entrevista coletiva, 8 jul. 2010).

A avaliação é considerada por Freitas $(1995,2003)$ como uma categoria fundamental para refletir sobre a escola capitalista e sua lógica de exclusão, garantindo sua função social nesta sociedade. Constitui um par dialético com os objetivos, estes, por sua vez, se expressam nas práticas avaliativas e envolvem relações de poder para a sustentação da organização do trabalho pedagógico da aula e da escola, além do controle disciplinar, tendo como fim a educação para a subalternidade da classe trabalhadora.

As falas das jovens expressam a possibilidade que o Conselho de Classe Participativo tem criado para romper com as estruturas de poder e coerção, incluindo o pensar sobre si, o outro e todas as funções e sujeitos da escola, no sentido de buscar melhorias nos encaminhamentos cotidianos.

O PPP (2009) no item do Marco Situacional coloca os limites da avaliação "diagnóstica, participativa e dialógica" na escola, localizando que as dificuldades de avanços encontram razões na resistência dos educadores em enfrentar o fato de avaliar, mas também serem avaliados. Tendo como concepção a organização pelos Ciclos de Formação Humana, o documento expressa a perspectiva da avaliação como central nos processos de questionamentos dos encaminhamentos pedagógicos, que 
envolvem a sala de aula e os demais espaços e momentos da escola. Aponta a necessidade de articulação com a família, que precisa estar inserida para garantir o acompanhamento dos seus filhos.

Em termos operacionais propõe-se no PPP (2009) a "superação da nota e classificação", buscando instrumentos para uma avaliação mais qualitativa, com a participação efetiva dos educandos durante o processo. $\mathrm{O}$ registro da avaliação inclui a Pasta de Acompanhamento, que segue toda a vida escolar do educando até sua saída e na qual se registram os avanços e dificuldades na aprendizagem, com espaço para os educadores, educandos e famílias; o Parecer Descritivo, em substituição ao boletim escolar, no qual se descreve o desenvolvimento de cada educando considerando os objetivos e conhecimentos trabalhados no semestre e que é lido no conselho de classe dos educadores para reescrita e/ou aprovação. Esses documentos não substituem as avaliações de cada disciplina, como as atividades de pesquisas, seminários, provas etc., ao contrário, valem-se também delas para obterem as informações necessárias de cada educando (PPP, 2009).

Como se pode notar, o Conselho de Classe Participativo foi um elemento enfático nas falas dos entrevistados. Ele é concebido como "espaço de divisão do poder da instituição escolar, avalia-se cada sujeito e cada instância da escola envolvida no processo educativo" (PPP, 2009, p. 54), sendo composto por três momentos, detalhados da seguinte forma:

$1^{\circ}$ Momento: No primeiro momento cada educando deverá elaborar uma auto-avaliação em forma de parecer descritivo do seu desempenho em classe, levando em consideração os elementos da aprendizagem e de participação coletiva na turma. O educador coordenador fará a avaliação da turma considerando os elementos arquivados na Pasta de Acompanhamento 
e a avaliação do coletivo dos educadores. Para isso a Equipe Pedagógica da escola apresentará anteriormente os critérios. $2^{\circ}$ Momento: No segundo momento o educador e educando coordenadores da turma com o apoio da Equipe Pedagógica sistematizarão as autoavaliações elaborando um parecer descritivo da turma e do colégio segundo os critérios estabelecidos em cada período. $3^{\circ}$ Momento: No terceiro momento será realizado um encontro onde o educando e educador coordenadores da turma apresentarão a sistematização. Todos os envolvidos no processo de avaliação serão ouvidos e após complementarão com análises, sugestões, questionamentos, desafios e até mesmos alertas e quais os passos a serem seguidos, como: replanejamento dos educadores, fazer conversa com os pais, registrar em atas os combinados e expondo-os. Participam deste momento a direção e/ou direção auxiliar, equipe pedagógica, os educandos e educadores da turma, bem como pais, membros do Conselho Escolar, APMF. (PPP, 2009, p. 54, grifos do autor).

Se os estudantes visualizam avanços na avaliação pela experiência de suas inserções no Conselho de Classe Participativo, os educadores em sua maioria, segundo o depoimento da vicediretora ${ }^{6}$, contrapõem-se à realização do mesmo, principalmente quando se referem ao terceiro momento, pois alegam se sentirem expostos e ameaçados, não compreendendo como alunos podem avaliar professor. Tal postura gera em cada semestre conflitos para a viabilização dos conselhos.

No que concerne ao que denominamos de dimensão da cultura, ela aparece nos relatos quando os jovens se referem às seguintes práticas pedagógicas: Projeto Viver em Harmonia e Momento Cívico, como exposto a seguir.

Um egresso trouxe a importância dessas práticas na sua formação, ampliando a sua capacidade de se comunicar e 
expressar em público, além disso, identificando-as como marcas diferenciais do Colégio Iraci.

Até me arrepio quando falo assim do Iraci, porque quando eu estudei ali acho que foi o lugar que eu me desenvolvi mais, até pra comunicação, assim, em reunião, que às vezes no meio do povo a gente tem vergonha de falar. Então ali foi um aprendizado que eu tive que sinceramente, nossa, quando lembro do Iraci, aprendi muito e cresci. Tinha aqueles momentos cívicos, as apresentação, né, Tinha muita coisa assim, que os alunos tinham que apresentar. Então ali foi um lugar que eu cresci e perdi até a vergonha. [...] Eu acho que a Iraci tem a vantagem, que eu acho que ela é diferente um pouco das outras. Ela tinha o coral, que foram pra Curitiba, uma vez. Então ela representou bem o próprio colégio, ela incentivou. Tanto no coral, mas também as aulas de música, a banda. (Elio, entrevista concedida à autora em 22 dez. 2010).

Uma jovem que num primeiro momento negou algum destaque na organização do Colégio, até porque nunca pode se envolver para além da aula devido ao fato de trabalhar em casa, posteriormente, visualizou as atividades do Projeto como diferentes em relação a outras escolas.

Não, acho que não teve grandes diferenças. [...] Não é bem assim, acho que tem diferença sim. Porque as outras escolas não têm teatro, aquelas outras coisas e nas outras escolas não tinha assim muito. Nunca me envolvi porque a mãe trabalhava, tinha que ficar em casa, tal. Assim, nunca me envolvi muito. (Adriana, entrevista concedida à autora em 20 dez. 2010). 
O coral foi a primeira manifestação artística a integrar o Projeto Viver em Harmonia, que começou em 2000 devido ao fato dos educadores perceberem a falta de lazer dos educandos, identificarem a presença forte da música em seu cotidiano e buscarem alternativas para o desinteresse, evasão e repetência enfrentados pela escola. Após intensa procura dos estudantes, em 2002 estabeleceu-se parceria com uma empresa das proximidades do colégio, a fim de viabilizar aquisição de materiais e a ampliação para o teatro, percussão, banda, música raiz e artesanato, que iniciou no ano seguinte. Em 2009, com o apoio do MST, o colégio passou a integrar o Programa Universidade Sem Fronteiras, realizado pela Secretaria de Estado da Ciência, Tecnologia e Ensino Superior, além do Programa Viva Escola, da SEED.

Ao comentar sobre as vivências no Colégio, a jovem Keli afirma:

O coral contribuiu bastante pra isso. Eu era um pouco tímida, né, ai desinibiu um pouco, questiona mais, vai procurar saber melhor. Foi o colégio que eu mais participei, né. Antes era, começava numa escola. Aí, o meu pai trabalhava de arrendatário, o patrão mandava embora, parava na metade, começava na outra, tinha que começar tudo de novo. Ai era sempre assim, nunca tinha uma continuidade e no Colégio Iraci que foi essa oportunidade. [...] E o coral, que era um momento de diversão, era muito bom. A gente cantava, se divertia, ria, fazia teatro, saia cantar nos outros lugares. Nossa, era bem legal. E as amizades, né. Amigos, assim, era bem importante e mexia com uma coisa de sentimento, que era bem legal. A professora era bem querida e tem coisas que levo até hoje. As viagens, que a gente saia, se divertia bastante. Que nem, eu nunca fui de sair muito, na comunidade não tinha muito lazer, né. Então, quando ia na escola que achava isso. Lá na escola tinha o Coral, tinha o teatro, tinha a música, tinha a banda. Então era 
um monte de coisa que a escola proporcionava. Ia pela escolha, nós escolhemos o coral porque se identificava. Eu depois ajudei a coordenar o coral por um período. Foi bem difícil, complicado, porque foi minha primeira experiência, tipo, eu na frente dos alunos assim, me sentia bem constrangida, bem tímida, até que levava, do jeito que eu sabia, do que tinha aprendido. Até quando eu pude eu levei, porque eu gostava, acho que foi bom. Nas apresentações sentia aquele frio na barriga e, mas nossa! (Keli, entrevista concedida à autora em $22 \mathrm{dez}$. 2010).

As reiteradas falas acerca do coral se relacionam com o fato de este ter sido o ponto de partida para o desenvolvimento de atividades culturais no Colégio, fazendo-se presente há cerca de dez anos na organização da escola e, portanto, sendo acessível a um número maior de estudantes por tempo mais longo.

Carla - Eu acho que lá na Vila também é o início do coral, um momento interessante pra quem participou, que proporcionava um espaço de lazer que a gente não tinha. A gente quase não podia sair, acho que a gente gostava de ir pra escola também pra encontrar os amigos, pra brincar, pra se divertir. Acho que as comunidades ainda não eram estruturadas, o acesso a própria cidade era muito pouco, então, o início do coral, do teatro, ajudou... Edilaine - É, eu fui uma das fundadoras do coral, participei no primeiro ano. Eu achei legal, porque eu nunca tinha participado assim, de nada mais diferente. $\mathrm{Na}$ época eu tinha muita vergonha assim, também, sabe. O teste que a professora fez no coral, nossa, foi terrível, eu quase morri, tive quase um troço lá. Isso que era só com ela, né, não era na frente de todos os alunos. Mas foi legal o coral, eu gostava de participar. Mas desisti logo também, não fiquei muito tempo. 
Carla - De fato, se falar da Iraci pra mim, eu não vou lembrar da sala de aula. Eu vou lembrar do coral, do teatro.

Edilaine - Sim, claro.

Carla - Dos projetos, de tudo aquilo que a gente fazia fora sala de aula.

Ederson - Os Momentos Cívicos também, né!

Carla - Alguns conseguiram fazer relação com a sala de aula sim, mas não a grande maioria.

Sonia - Eu também lembro mais dos projetos. Eu participava do teatro, então teve o teatro que a gente fez sobre drogas. Aí veio uma viagem pra Faxinal do Céu, só que lá eu não aproveitei muito, porque aqui a gente se sente a vontade e lá como fui só eu, me senti perdida, porque tinha gente de outras escolas que estavam em grupos, e daqui só tinha eu, mas foi legal, participei de várias oficinas.

Carla - Os projetos também, não conheço outro espaço que faça dessa forma. Porque a maioria deles são ensaios, muito do ponto de vista do espetáculo, vai, ensaia e apresenta. Acho que a escola consegue inverter a lógica aqui. Vamos ensaiar, vamos apresentar, mas o trabalho acontece de uma outra forma. Há uma formação pela arte, em tentar pelo menos discutir algumas coisas, estudar, não só o ensaio pelo ensaio. (Entrevista coletiva concedida à autora em 8 jul. 2010).

O Momento Cívico aparece no trecho acima, bem como no depoimento a seguir:

E até os momentos cívicos que nas outras escolas que eu estudei não tinha. Acho que ela é mais adiantada que as outras. Os Momentos Cívicos eram por turma, uma vez por semana. Um dia era uma turma que apresentava um tema, tipo, meio ambiente, conforme combinava no dia. A turma mesmo se organizava, até que era tranquilo, pra 
falar a verdade era mais as meninas que puxavam e nó íamos juntos, no embalo delas (Elio, entrevista concedida à autora em 22 dez. 2010).

Esta é uma prática que encontra referência nos princípios educativos do MST, sobretudo no Caderno de Educação n. 9 (MST, 1999) trazendo à tona a característica da mística e dos diferentes tempos educativos na organização do trabalho da escola. No PPP (2009) está orientada, sobretudo, a partir da vinculação com as matrizes da Pedagogia do Movimento, especificamente a denominada como "Pedagogia da cultura".

O Curso de Formação de Docentes traz presente continuamente a mística em seus tempos/espaços de formação, efetivamente nas aberturas e fechamentos dos Seminários citados anteriormente, dado afirmado pela coordenadora pedagógica ${ }^{7}$ do curso.

Uma das jovens expressa os seus aprendizados:

Kesia - E o que ficou muito também pra mim mesmo, apesar de sempre estar na questão do Movimento, nos assentamentos e acampamentos, é a construção de aprender a mística. O que ficou foi mística (Entrevista coletiva concedida à autora em 8 jul. 2010).

De uma maneira mais geral encontramos nos PPPs (2002, 2009) os pressupostos que fundamentam a dimensão cultural das práticas pedagógicas na escola quando tratam da visão acerca da formação humana e dos princípios assumidos, entre eles a "Educação para a transformação social" e a "Educação para as várias dimensões do ser humano" (PPP, 2009, p. 23).

A definição de cultura é apoiada pelas "Diretrizes Estaduais da Educação do Campo" e está assim estabelecida no PPP (2009, p. 26): 
Cultura aqui é entendida como toda produção que se constrói a partir das inter-relações do ser humano com a natureza, com o outro e consigo mesmo. Não pode ser resumida apenas a manifestações artísticas, devendo ser compreendida de modo mais abrangente, observando-se os modos de vida dos sujeitos, seus costumes, relações de trabalho, familiares, religiosas, sociais, dentre outras. Estes são elementos culturais que caracterizam os diferentes sujeitos no mundo e, portanto, os diferentes povos do campo.

Embora esteja presente no PPP (2009) nos Marcos Situacional e Conceitual, no Operacional não encontramos nenhuma indicação quanto à dimensão cultural. Mesmo assim, as práticas são realizadas, como podemos perceber nos relatos dos egressos. Os limites se dão pelo fato das atividades do Projeto ocorrerem no contraturno e acontecerem como atividades extra, não tendo local apropriado. Além disso, há pouca participação dos estudantes, principalmente do Ensino Médio, posto que em sua maioria precisam ajudar suas famílias no plantio, colheita e afazeres doméstico, não podendo se ausentar de casa fora do horário escolar.

Já o Momento Cívico, por ser parte constitutiva da organização do trabalho pedagógico durante o período escolar, acaba envolvendo todos os educandos, incluindo também os educadores coordenadores de cada turma. Entretanto, é algo que todos têm que assumir, independente da vontade ou identificação. Como ocorre no Conselho de Classe Participativo, os professores oferecem resistência, por acreditarem estar perdendo tempo de suas aulas. Os educandos encontram um espaço de auto-organização, que nem sempre é efetivado, como na fala do jovem acima, em que afirma que eles, os meninos, "iam junto no embalo" das meninas.

Interessante destacar que entre as entrevistadas duas jovens após o término do Ensino Médio retornaram para a escola para 
coordenar as atividades do Projeto, uma à frente do grupo de coral e a outra do teatro. Em decorrência disso, passaram a participar de atividades formativas do Setor de Comunicação e Cultura do MST, sendo que uma delas no momento da pesquisa de campo ainda contribuía com atividades ligadas a essa instância.

Nas discussões acerca do Ensino Médio com a perspectiva de uma formação integrada apresentadas no início desse texto, a cultura está colocada como um dos três pilares, articulada ao trabalho e à ciência (FRIGOTTO; CIAVATTA, 2004). No entanto, não encontramos nesses autores nenhum detalhamento do que se concebe como cultura e de que forma esta se relaciona com a tecnologia e o trabalho na organização escolar. Apenas o trabalho aparece com bastante ênfase nas discussões, acerca do qual se clareiam as concepções e as controvérsias, ficando uma lacuna no aprofundamento da cultura como uma dimensão formativa basilar no Ensino Médio.

Finalmente, a valorização da história/memória do assentamento subsidiou a apreensão dos elementos constitutivos da organização do trabalho pedagógico da escola investigada. A vice-diretora ${ }^{8}$ afirmou o envolvimento do Colégio nas comemorações do aniversário do assentamento, em 17 de abril, e de como nesse momento, vivido anualmente, é reforçado o processo que envolveu a conquista do espaço em que os educandos residem.

Além disso, os jovens relataram a importância do reconhecimento das origens do assentamento, e em consequência da própria escola, estimulada e viabilizada pelas práticas pedagógicas do Colégio Iraci, como destacado nos trechos a seguir:

Carla - Eu vim pra cá há nove anos. [...] foi na escola que eu entendi que isso aqui era um assentamento, que houve uma ocupação, que era de Sem Terra, [...] e mesmo essa coisa de ser chamado de Sem Terra, que até então a 
gente não tinha essa identidade. Nós fomos criando com a escola também, no meu caso. [...].

Sonia - Acho que é porque a gente não entendia, né, não conhecia a história. Mas depois que a gente começou a entender e começaram a contar a história, a gente começou a ter orgulho de quem enfrentou, tudo que passaram, pra ter o que tem hoje. E daí, depois que a gente conheceu a história que a gente começou a gostar e hoje também, se me disserem que eu sou Sem Terra eu também gosto, eu gosto disso. É porque agora a gente tem conhecimento, antes não era a realidade da gente, por isso.

Thaile - E a escola ajudou a gente a aceitar isso.

Carla - Não só aceitar, mas entender também, pra grande maioria, porque, por exemplo, quando eu estudei no Ensino Médio. [...] os vários momentos pra além da sala de aula, que a gente viveu, que ajudou a fazer isso. [...] por aí a gente relembrava a história todo ano, comemorava o 17 de abril, aprendia o que era o 17 de abril na escola. Eu acredito que a escola fez essa formação, que outro espaço talvez deveria fazer mas não acontecia.

[...]

Kesia - Quando vai surgindo o assentamento parece que isso vai se perdendo. Toda uma caminhada que teve. Que nem aqui, tem uma história super importante que não se vê mais essa história, que tá se perdendo isso no caminho. Quem tá buscando isso aqui é a Iraci, que tá tentando levar essa história assim, mas que a comunidade não tá contribuindo muito.

[...]

Ederson - Por exemplo, nós, que faz cinco anos e poucos que to morando ali. Que nem meus pais mesmo, muitas coisas eles não sabem. E coisa assim que eu sei sobre a história da comunidade, do assentamento eu fiquei sabendo mais na escola [...]. 
Marines - Então uma das coisas que o Iraci, o Colégio tenta fazer é estar relembrando a história pros novos que chegam. [...]

Joice - Aqui muitas pessoas sabem da história do assentamento porque a escola resgata isso, porque os assentados tão deixando a história. (Entrevista coletiva concedida à autora em 8 jul. 2010).

Além das falas, a publicação de um livro denominado Escola em movimento, a conquista dos assentamentos, que envolveu educadores, educandos e familiares, reforça a preocupação da escola pelo registro e permanente relembrar das lutas, sofrimentos e alegrias que envolveram a conquista do Assentamento Marcos Freire e do Colégio Iraci (HAMMEL; SILVA; ANDREETA, 2007).

A sistematização do PPP (2009) inicia com três capítulos que retomam a história da escola, destacando as origens, o significado do nome e a presença de diferentes sujeitos no processo de constituição do Colégio Iraci. A matriz da "Pedagogia da história" é um fundamento teórico assumido, entendido como "[...] o cultivo da memória e da compreensão, do sentido da história e da percepção, de ser parte dela, não apenas como resgate de significado, mas como algo a ser cultivado e produzido." (PPP, 2009, p. 30). Em termos operacionais, da mesma maneira que ocorre com a dimensão cultural, não há nada especificado em relação às práticas pedagógicas que envolvem a valorização da história/memória do assentamento.

No término do PPP-FD (2008, p. 11) afirma-se o esforço em buscar construir uma proposta político pedagógica para a formação docente considerando o contexto dos educandos. Esta é uma das razões que torna "necessário considerar a história da escola, o caminho que percorreu paralelamente às lutas do campo e por direitos sociais", processo esse que precisa ser socializado com todos os sujeitos que compõem a escola. 
Considerando as possibilidades da educação profissional, mediante sua realidade e historicidade no sistema educacional brasileiro, Ciavatta (2005) denomina sete pressupostos para a sua realização enquanto formação integrada e humanizadora e dentre eles encontra-se o resgate da escola como lugar de memória. Afirma a autora:

Como elemento aglutinador, gerador de coesão social, a escola deve se tornar um lugar de memória, de resgate das identidades, da compreensão do presente, incorporando as dificuldades, as lutas e as conquistas do passado, suas representações na forma de imagens e de documentos, seus símbolos carregados de história e de significados. (CIAVATTA, 2005, p. 100-101).

A história e a memória são dinâmicas e, por isso, quando as lutas sociais, os fatos e acontecimentos que marcaram tantas famílias no acampamento, na luta pela terra, são constantemente retomados, torna-se possível a formação de uma identidade, um enraizamento que fortalece a constituição como ser humano. Esse processo também ocorre com aqueles que não viveram necessariamente os momentos relembrados, mas que, ao conhecerem, assumem para si o fato de serem Sem Terra e junto a essa identidade específica articula-se a consciência de fazer parte de algo mais amplo, da classe trabalhadora. Como afirma o depoimento da jovem no trecho citado, mais do que "apenas aceitar uma situação", possibilita compreender os condicionantes que envolvem as relações sociais capitalistas, por exemplo, com a concentração da terra e expropriação dos trabalhadores rurais.

Assim, sinteticamente retomando as questões acerca dos determinantes e as possibilidades na formação dos jovens do Colégio Estadual do Campo Iraci Salete Strozak, consideramos que embora a sociabilidade do capital imponha uma formação unilateral, é possível perceber anúncios de uma 
contrainternalização, como nos dizeres de Mészáros (2005), tendo em vista a busca pela transformação social e emancipação humana, as quais se a escola não pode realizar sozinha, também não pode se negar a prestar sua "contribuição imprescindível".

\section{Referências}

CALDART, Roseli S. Pedagogia do Movimento Sem Terra: escola é mais do que escola. Petrópolis: Vozes, 2000.

CIAVATTA, Maria. A formação integrada: a escola e o trabalho como lugares de memória e identidade. In: FRIGOTTO, Gaudêncio; CIAVATTA, Maria. (Orgs.). Ensino Médio integrado: concepções e contradições. São Paulo: Cortez, 2005.

ENGELS, Friedrich. Princípios básicos do comunismo. Obras escolhidas. Moscovo: Progresso; Lisboa: Avante!, 1982.

FREITAS, Luiz Carlos de. A lógica da avaliação. In: . Ciclos, seriação e avaliação: confronto de lógicas. São Paulo: Moderna, 2003.

. Crítica da organização do trabalho pedagógico e da didática.

Campinas: Papirus, 1995.

FRIGOTTO, Gaudêncio. Concepções e mudanças no mundo do trabalho e o Ensino Médio. In: ; CIAVATTA, Maria (Orgs.). Ensino Médio integrado: concepções e contradições. São Paulo: Cortez, 2005.

Sujeitos e conhecimento: os sentidos do Ensino Médio. In: ; CIAVATTA, Maria (Orgs.). Ensino Médio: ciência, cultura e trabalho. Brasília: MEC; SEMTEC, 2004. 
;CIAVATTA, Maria. A busca de articulação entre trabalho, ciência e cultura no Ensino Médio. In: (Orgs.). Ensino Médio: ciência, cultura e trabalho. Brasília: MEC; SEMTEC, 2004.

; ; RAMOS, Marise N. A gênese do Decreto n. 5154/2004: um debate no contexto controverso da democracia restrita. In: FRIGOTTO, Gaudêncio; CIAVATTA, Maria (Orgs.). Ensino Médio integrado: concepções e contradições. São Paulo: Cortez, 2005.

GARCIA, Sandra R. de Oliveira. A educação profissional integrada ao Ensino Médio no Paraná: avanços e desafios. Tese (Doutorado em Educação) - Programa de Pós-Graduação em Educação, Universidade Federal do Paraná, Curitiba, 2009.

HAMMEL, Ana C.; JANATA, Natacha E. Formação de educadores do campo: a experiência educativa na organização dos estágios desde a Pedagogia do movimento. In: SAPELLI, Marlene Lucia S. Vozes de resistência: sobre práticas educativas nos tempos e espaços ocupados pelo MST. Guarapuava: Unicentro, 2010.

HAMMEL, Ana C.; SILVA, Nilton C.; ANDREETTA, Ritamar. Escola em movimento: a conquista dos assentamentos. Colégio Estadual Iraci Salete Strozak. Rio Bonito do Iguaçu, 2007.

KUENZER, Acácia. Construindo uma proposta para os que vivem do trabalho. 4. ed. São Paulo: Cortez, 2005.

MARX, Karl. Instruções para os delegados do conselho geral provisório. As diferentes questões. Obras escolhidas. Moscovo: Progresso; Lisboa: Avante!, 1982.

O capital: crítica da economia política. Livro 1, v. 1, XIII. Rio de Janeiro: Civilização Brasileira, 2010.

MÉSZÁROS, István. A crise da educação. In: A teoria da alienação em Marx. São Paulo: Boitempo, 2006. 
MST. Como fazemos a escola de educação fundamental. Caderno de Educação. São Paulo: MST, n. 9, 1999.

. Documento Final do $1^{\circ}$ Seminário Nacional sobre Educação Básica de Nível nas áreas de Reforma Agrária. In: CALDART, Roseli S. (Org.). Caminhos para transformação da escola: reflexões desde práticas da licenciatura em educação do campo. São Paulo: Expressão Popular, 2010.

. Educação básica de nível médio nas áreas de reforma agrária: textos de estudo. Boletim da educação. Veranópolis: ITERRA, edição especial, n. 1, set. 2006.

PROJETO POLÍTICO PEDAGÓGICO. Rio Bonito do Iguaçu: Colégio Estadual Iraci Salete Strozak, 2009.

PROJETO POLÍTICO PEDAGÓGICO DO CURSO DE FORMAÇÃO DE DOCENTES. Rio Bonito do Iguaçu: Colégio Estadual Iraci Salete Strozak, 2008.

RAMOS, Marise N. Concepção do Ensino Médio integrado à educação profissional. 2006. Texto para Seminário de Ensino Médio da Superintendência de Ensino Médio da Secretaria de Educação do Estado do Rio Grande do Norte, em Natal e Mossoró, agosto de 2006.

. O projeto unitário de Ensino Médio sob os princípios do trabalho, da ciência e da cultura. In: FRIGOTTO, Gaudêncio; CIAVATTA, Maria (Orgs.). Ensino Médio: ciência, cultura e trabalho. Brasília: MEC; SEMTEC, 2004.

SEED. Proposta pedagógica curricular do Curso de Formação de Docentes para a educação infantil $e$ anos iniciais do ensino fundamental, em nível médio, na modalidade normal. Curitiba: SEED, 2006. 


\section{Notas}

* O trabalho integra a tese de Doutorado em Educação intitulada "Juventude que ousa lutar!': trabalho, educação e militância de jovens assentados do MST", defendida em 2012 sob a orientação da $\operatorname{Prof}^{a}$ Dr $^{a}$ Celia R. Vendramini, no Programa de Pós-Graduação em Educação da UFSC.

${ }^{1}$ Doutora em Educação pela UFSC, coordenadora da Escola dos Sonhos, Florianópolis (SC). E-mail: <nejanata@yahoo.com.br>.

${ }^{2}$ Iraci Salete Strozak foi uma importante liderança do MST que desenvolveu trabalhos em várias regiões do Paraná, assumindo diferentes funções, sobretudo no Setor de Educação do Movimento. Entre 1996 e 1997, acompanhou o processo de formação das escolas no acampamento e assentamento da fazenda da Giacomet-Marodin. Faleceu em acidente de trânsito em novembro de 1997, justamente quando estava buscando completar o seu processo de escolarização.

${ }^{3}$ Passaremos a adotar essa nomenclatura abreviada da escola, por ser dessa forma que os jovens, bem como professores e a comunidade a denominam em seu cotidiano.

${ }^{4}$ Ana Cristina Hammel (entrevista concedida à autora em 8 jul. 2010).

${ }^{5}$ Os trechos dizem respeito especificamente ao tema da avaliação. O símbolo [...] significa que houve outras falas, mas que não tratam especificamente dele por isso foram não foram consideradas nesse momento.

${ }^{6}$ Ana (entrevista concedida à autora em 8 jul. 2010).

${ }^{7}$ Tatiane Navroski (entrevista concedida à autora em 22 dez. 2010).

${ }^{8}$ Ana (entrevista concedida à autora em 8 jul. 2010). 